\title{
The Global System for Mobile Communications (GSM) for Wireless Home Security with Arduino and Web CAM
}

\author{
Abu Bakar Ibrahim, Che Zalina Zulkifli, Hafizul Fahri Hanafi and Fatikah Anis Zakaria
}

\begin{abstract}
This project presents the global Mobile Communication System (GSM) for Wireless Home Security with Arduino and Web CAM. This study aims to expand the use of Arduino and GSM as one of the tools of home security system. The second is to develop a relatively inexpensive and easy-to-use home security system. The third is to develop a security system with the concept of self-monitoring. The fourth is to make it easier for users to be more sensitive to their home condition by simply receiving SMS. The methodology that has been used in developing this project is the Engineering Design Process model. Generally, this model has 9 phases. Each phase found in this model can help the researcher ensure that the product developed can achieve the set objectives. Researchers have analyzed all data and can conclude that 70 percent of respondents agree that the system designed can reduce theft and improve home security features. Respondents also agreed that this system could be applied in real situations. In addition, all respondents agreed that the system is safe to use, with a total percentage of 86 percent agree and 14 percent strongly agree. The final result could illustrate that this developed system can provide benefits and benefits to users.
\end{abstract}

Index Terms - GSM, Home security, Arduino, Web CAM.

\section{INTRODUCTION}

Today, information and communication technology (ICT) is growing and evolving rapidly. Thus, other technologies also continue to evolve so that the systems developed can compete with the latest technology. Home security systems cannot be fully controlled by humans, but with the advent of the latest technology and microcontrollers, especially on the Internet of Things (IoT), it has given a new face to home monitoring and security systems. [1]. The Global System for Mobile communications (GSM) Wireless Home Security with Arduino and Web Cam is a home security system developed to reduce theft case and increase home security features. This system uses GSM module and Arduino board as main components. GSM or Global System Communication could send a short messaging system (SMS) to users in the event of something in their home. The use of webcam also helps the user to control the situation at home. An output makes the system one of the most effective techniques in securing the risk of home-breaking cases and making them different systems with existing home security systems [2], [3]. The choice of the component which is relevant to the purpose of the study is significant in ensuring that the developed system can benefit the users, in turn, can be used as a home security system.

The main factor in developing this project is based on frequent problems where most of the existing home security systems use the system alarms only, and users cannot find out what has happened in their home until told by neighbors or authorities. In addition, this system also focused on the use of a less complex and easy circuit, so it is easy to install and easy to use by users. The cost used to develop this project is also reasonable in ensuring that it is affordable for the existing security system. Nevertheless, the use of Arduino and GSM software, as well as other electronic components, necessitates the user to have their skills in facilitating the user to use them [4].

\section{LITERATURE REVIEW}

Studies should be carried out to collect information, obtain and analyze the information needed to develop a quality system. This study is very important in implementing the project. This development process cannot be carried out correctly if the information and knowledge to develop the project is inadequate. Therefore, all the necessary information needed in project development needs to be identified and predefined. Various methods can be used to gather the information necessary, such as information from reading materials such as journals, web, and related books. Additionally, keep an eye on the home security system in the market where it covers the system's advantages and disadvantages. In addition, researchers can also obtain the desired information by interviewing users in Malaysia. All data received will go through the evaluation process and will be analyzed in the process of developing this system [5], [6].

\section{A. Home Security System}

Historically, home security systems have long been developed by Marie Van Brittan and her husband, Albert Brown of New York. In 1966, Marie Van Brittan and her husband, Albert, introduced an electronic security system to reduce crime rates at that time. With the knowledge available in the field of electronic engineering, they created a closed circuit camera (CCTV) system to monitor the residence [7]. As we all know that technology is changing so fast; every year, many designs and developments on home security systems are designed. The creators strive to produce security systems using the latest technologies such as Arduino, raspberry pi and sensors. Sensory home security systems and 
CAM webs require advanced technologies and methods that need to be connected wireless and ensure real-time operation and threat indicators [8]. The final output can be regarded in the development of the current home, where the idea of a good life has changed. At the same time, home security focuses on current technological trends that use digital, wireless, and the Internet of Things [9], [10]. Ordinarily, we have two types of home security systems widely used: webbased systems (WBS) and telephone-based systems (PBS). For phone-based control systems, it is performed by a global system for mobile communication networks. For this webbased system, it is done via the internet or wireless router.

\section{B. Web-based Home Security System}

Fig. 1 depicted a web-based system diagram. The web servers and home guards play an essential role in Web-based home security systems. The web server controls an interfaced website that recognizes users to control the system. Typically, real-time monitoring of home conditions is done through a web browser through a personal digital assistant (PDA), mobile phone and laptop used to access the internet. The laptop is connected to the internet via a local access network cable or local wireless access network (WLAN). In addition to that, the PDAs will be connected to the internet via WLAN [11].

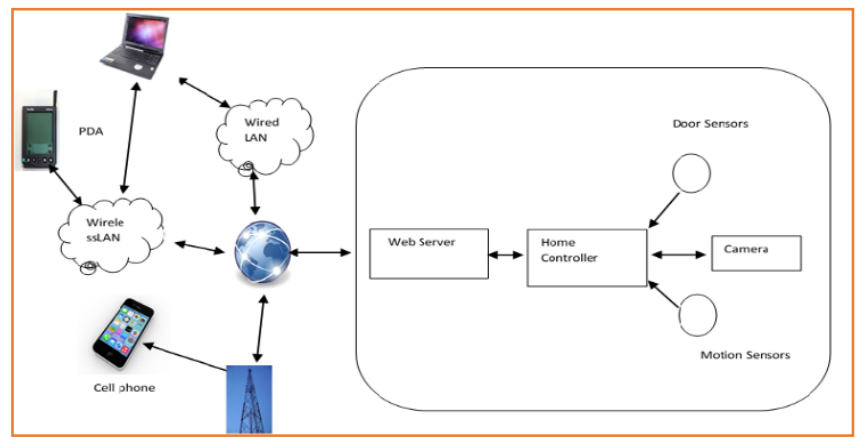

Fig 1. Web-based System [11].

Mobile phones are connected to internet services provided by mobile service companies. When the sensor detects any movement, a warning message will be sent to the user through the website. To show that, the users can verify the alarm after watching the home situation through devices like cameras installed in their home. Despite this, the Web-based systems require high-cost devices such as laptops or PDAs. Monthly internet service makes this web-based system a high-cost system [12], [13].

\section{Home Based Security Systems}

Fig. 2 illustrates a telephone-based system where users can activate the home alarm when leaving home. When a person passes through the sensor range, for example, the alarm will be notified through the PSTN system on the door sensor. Finally, the next PSTN will call the alarm monitoring company involved or directly to the homeowner [15], [16].

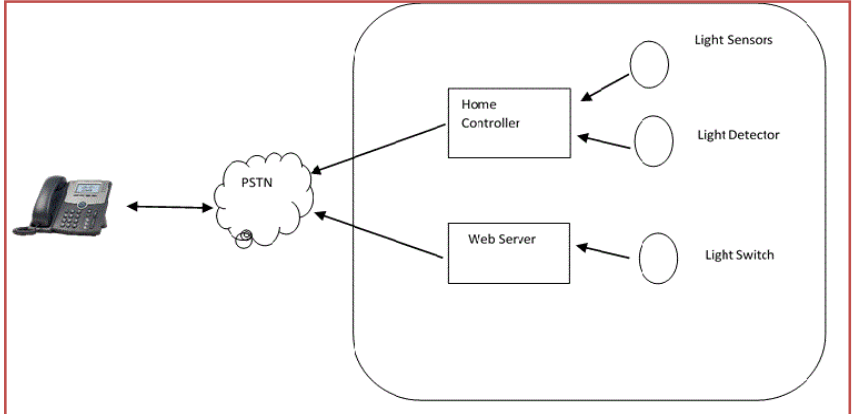

Fig. 2. System-based PSTN [14].

\section{DESIGN AND DEVELOPMENT}

The Arduino IDE software was used to generate program codes for this home security system. The pins used for connecting between components and the Arduino board have been set in a program built using this software [17]. The researcher has influenced the pins used in accordance with the design of the system. Built-in program code is based on the programmer's purpose and objectives, where the programmer has been able to detect movement within the sensor area, is turned on. Next, GSM will send a short message to the user to alert the user. The following are the programs used to enable the system to function correctly [18]. Moreover, Fig. 3 depicted the circuit of project development using Arduino Board components like UNO, GSM, and sensor.

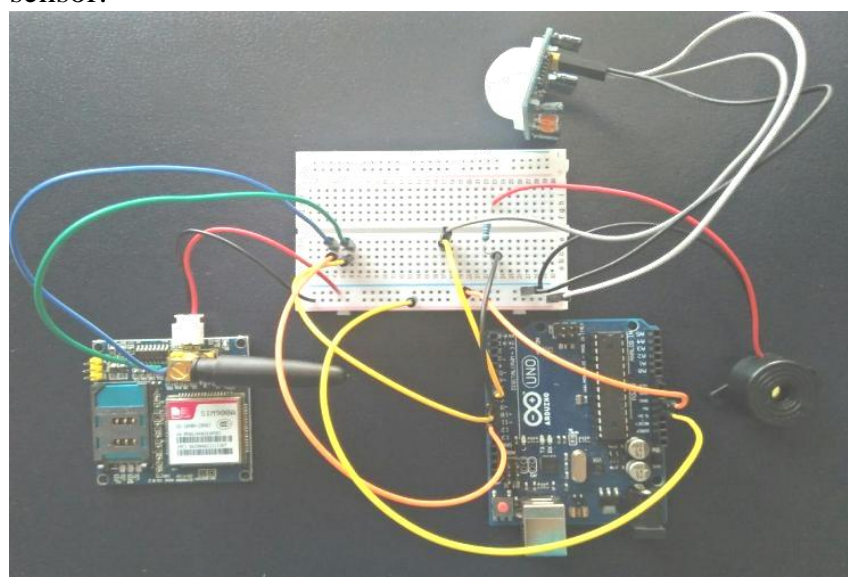

Fig 3. The Circuit of Project Development.

\#include $<$ Softwa reSerial.h $>$

SoftwareSerial mySerial $(9,10)$;

int sensor $=7$; //The output of PIR sensor connected to pin 7

int buzzer $=8 ; / /$ buzzer connected at pin 8

int sensor_value; $/ /$ variable to hold read sensor value int sms_count $=0$;

void setup0

\{

pinMode(sensor:INPUT); // configuring pin 7 as Input pinMode(buzzer,OLTPUT); // configuring pin 8 as OUTPUT mySerialbegin $(9600)$;

\}

void loop0

\{

Check_Burglar0;// subroutine to check sensor status and activation of outputs 


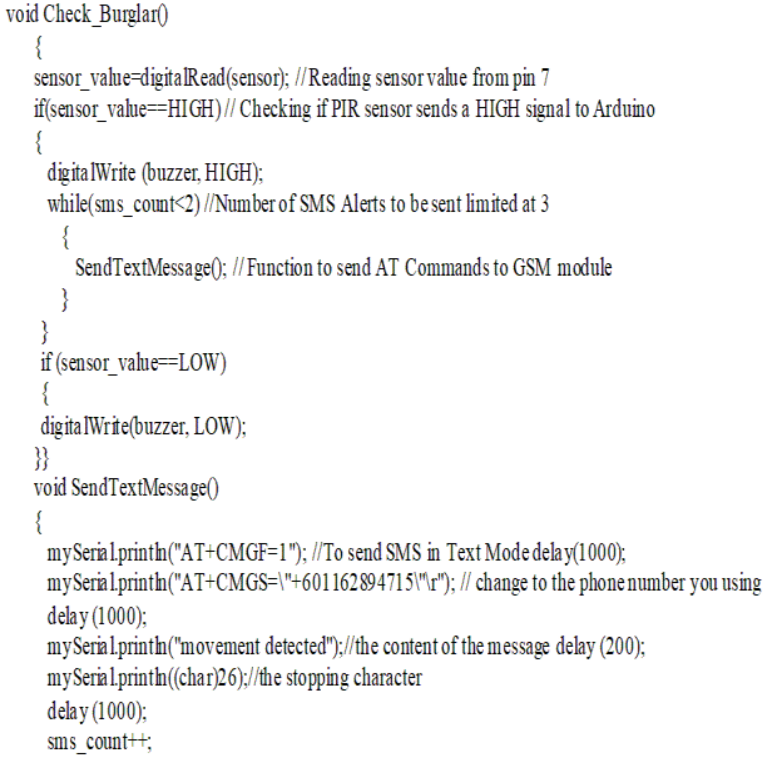

The process of designing a project is one of the essential elements to consider in ensuring that the design is in line with the system being developed so that the components used work well. Clearly, the researchers do a little bit of research to choose the appropriate design for placing the PIR sensor. Indeed, the researchers have decided to place the PIR sensor on the end of the house wall so that the sensor utilized will work properly [19], [20]. The diagram below shows the prototype design that the researcher has built.

\section{RESULT AND DISCUSSION}

The system was developed to improve the home security features and to reduce the risk of home breaking. After informing the respondents, the researcher should seek feedback from the respondents concerning this home security system's effectiveness. Although, the researcher obliges to determine whether the developed system has achieved its objective or not. Moreover, the result explicates the percentage of respondents who agree with the significance of this system. Most respondents agree on this system's efficacy in improving home security features based on the data gathered. The data results are indisputable when 63 percent of respondents gave a 5 (strongly agree) scale to the subsequent statement while another 37 percent rated a 4 (strongly agree). In conclusion, the researcher can be inclined to think that the research objective has been accomplished following the respondents' large scale.

\section{CONCLUSION}

As technology advances today, the purpose of technology in everyday life is run-of-the-mill. Various benefits of technology have been applied in our daily lives to ensure the well-being of our lives. Therefore, the system is being developed using today's technologies such as sensors and GSM modules, and mobile phones to decrease Malaysia's home breakage rates. With this system, it allows users to monitor home security from time to time throughout their absence. In conclusion, the developed home security system certainly benefits and benefits consumers. The system also enhances home security features, and the consumer can afford it at a lower cost compared to existing security systems on the market. As well, the home breakdown rate could be also be reduced with this home security system.

\section{REFERENCES}

[1] A.A. Olanipekun, O.K. Boyinbode (2016), A RFID Based Automatic Attendance System in Educational Institution of Nigeria. International Journal of Smart Home, Vol 9(12), 1-10.

[2] Abhijit Karle, Jyoti Borole (2016), Embedded Web Server Based Management and Monitoring for Educational Institute: A Survey. International Journal of Innovation Research in Science, Engineering and Technology, Vol 5(1), 1-6.

[3] Arulogan O.T., Olatunbosun A., Fakolujo O.A, Olaniya O.M., (2013), RFID Based Students Attendance Management System. International Journal of Scientific \& Engineering Research, Vol 4(2), 1-9.

[4] Barid Baran Nayak (2015), RFID Based Attendance Management System using Labview. India: Department of Electronics \& Communication Engineering.

[5] Chiagozie G. O., Nwaji G. O. (2012), Radio Frequency Identification (RFID) Based Attendance System with Automatic Door Unit. Academic Research Journal, Vol 2(2), 1-16.

[6] Farhan M. N., Nivash S., Chandran Monisha A. \& Chandran Mnjusha A. (2016), Interior Tracking with Automatic Attendance and Reporting System. Indian Journal of Science and Technology, Vol 9(30), 1-5.

[7] Harmida Binti Arobi (2011), In-Vehicle Signing System Using FRID (Master's thesis, Universiti Teknikal Malayisa Melaka, Malaysia).

[8] Krenare R. Pireva, Jeton Siqeca, Shkelqim Berisha (2013), RFID: Management System for Students' Attendance. $15^{\text {th }}$ Workshop on International Stability, Technology, and Culture the International Federation of Automatic Control, Vol 8, 3-4.

[9] K. Srinivasa Ravi, G.H. Varun, T. Vamsi, P. Pratyusha (2013), RFID Based Security System. International Journal of Innovative Technology and Exploring Engineering (IJITEE), Vol 2(5), 1-4.

[10] Li Jiang \& Yan Li (2012), Attendance Technology on Campus Research and Application. National Conference on Information Technology and Computer Science (CITCS), 40-42.

[11] Media Anugerah Ayu, Member IACSIT, Barroon Ismaeel Ahmad (2014), TouchIn: An NFC Supported Attendance System in a University Environment. International Journal of Information and Educational Technology, Vol 4(5), 1.

[12] Muhammad Nurhalim Bin Mohd Tunin (2016), Intelligent Trace Attendance System (I-TAS) (Undergraduate's thesis, Universiti Teknologi Malaysia, Malaysia).

[13] Nor Amiyana Binti Mohd Alias (2011), Attendance and Access Control System Using RFID (Undergraduate's thesis, Universiti Teknikal Malaysia Melaka, Malaysia).

[14] Nurbek Saparkhojayev, Selim Guvercin (2012), Attendance Control System based on RFID Technology. IJCSI International Journal of Computer Science, Vol 9(1), 1-4.

[15] Priyanka Sahare, Pranali Gaikwad, Snehal Narule, Nutan Thakre, Puja Chandekar, RTMNU Nagpur (2015), RFID Technology Based Attendance Management System. International Journal of Engineering and Computer Science, Vol 6(3), 1-6.

[16] Rohit Chandrashekar, Jayeshree Shinde, Dashrath Mane (2013) Importance and Analysis of RFID in Attendance System. International Journal of Emerging Science and Engineering, Vol 1, 1-3.

[17] Shashank Shukla, Shailee Shah, Pooja Save (2013), RFID Based Attendance Management System. International Journal of Electrical and Computer Engineering (IJECE), Vol 3(6), 784-790.

[18] Tanpure T. \& et. al (2013), Online Student Monitoring System Using Passive RFID. International Journal of Innovation Research in Computer and Communication Engineering, Vol 1(2), 1-7.

[19] Wee Pek Ling (2012), Integrated Staff Attendance System (Undergraduate's thesis, Universiti Malaysia Pahang, Malaysia).

[20] Zatil Singhal, Rajneesh Kumar Gujral (2012), Anytime Anywhere Remote Monitoring of Attendance System based on RFID using GSM Network. International Journal of Computer Application, Vol 39(3), 15 . 


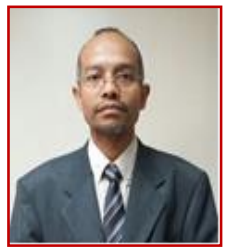

Abu Bakar Ibrahim is an Associate Professor in the Computing Department, Faculty of Arts, Computing and Creative Industry at Sultan Idris Education University, Malaysia. He is received a B.Sc. in Electrical Engineering and a Master's Degree from Universiti Teknologi Malaysia (UTM)in 1998 and 2000, respectively. He received a Ph.D. in Electronic Engineering (Communication) from Universiti Teknikal Malaysia Melaka (UTeM) in the years 2013. He had professional teaching experience in the development of Low Noise Amplifier (LNA), Radio Frequency Communication System, Instructional Technology, Engineering Mathematics, Wireless Communication and Engineering Education. He has developed confidence and interest in researching and teaching areas to enhance creative Innovation in Engineering, Science \& Technology.

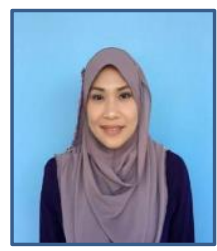

Che Zalina Zulkifli is an Associate Professor in the Computing Department, Faculty of Arts, Computing and Creative Industry at Sultan Idris Education University, Malaysia. She had over 20 years of professional teaching experience as academia and active researcher in the Electronics \& Electrical Engineering, Information Technology, Embedded System, Industry Creative \& Networking area Experience as a Test Engineer in the multinational company. Her research projects have collaborated with a multinational company and government agencies, which contributes to a network that leads to new ideas and concrete research projects. The developed automation projects that focused on Sensor Monitoring, Embedded System, Software, loT and Wireless Communication fields have been successfully adopted by the industry to date. A total of more than a million Ringgit has been generated as an income to the University mainly from the Research Grant, Commercialization of innovative research products and also the services as a principal consultant. Expertise in the agriculture sector with a new invention to improve crop production adopted high technology. She is sincerely dedicated to the very wise in the green project about recycling and reuse of waste. She has won several international awards and national awards. She has developed confidence and interest in researching and teaching areas to enhance creative Innovation in Engineering, Science \& Technology.

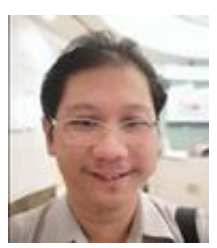

Hafizul Fahri Hanafi is a senior lecturer of the Computing Department, Faculty of Arts, Computing and Creative Industry at Sultan Idris Education University, Malaysia. He has so many experiences, over 17 years of experience in academia, and an active researcher in many research activities and research grants in recent years. He also contributed so much research peculiarly on augmented reality in education and even human-computer interaction. He was also involved in current government activities that contributed to alleviate digital learning for the rural areas. The expertise of development is needed to enhance Information Technology usage peculiarly on the current demands of mobile applications and development. Furthermore, his expertise also converted into academic articles that also be a part of academician and published in highly-tier journals.

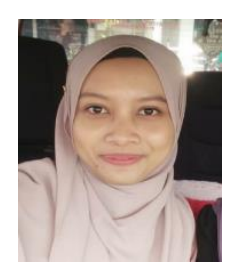

Fatikah Anis Zakaria is currently pursuing Master of Information Technology at Sultan Idris Education University, Malaysia. She received her Bachelor's degree in Education Computer Aided Design Technology from Sultan Idris Education University, Malaysia in 2018. She has a background in technology and holds keen interests in the area of teaching and engineering to assure progressive Innovation in Engineering, Science \& Technology. 